\title{
IoT Based Electric Energy Meter
}

\author{
Pratik P. Bakshi ${ }^{1}$, Akshay S. Patil ${ }^{2}$, Akshay S. Gavali ${ }^{3}$, Prof. Vibha U. Patel ${ }^{4}$ \\ BE Student, Electronics \& Telecommunication, MIT College of Engineering, Pune, India ${ }^{1,2,3}$ \\ Assistant Professor, Electronics \& Telecommunication, MIT College of Engineering, Pune, India ${ }^{4}$
}

\begin{abstract}
This research is to design an automated electric meter reading and billing system. It will replace human working system for taking reading. It will be helpful in knowing the daily electricity usage. The proposed system design eliminates the human involvement in Electricity maintenance. The Buyer needs to pay for the usage of electricity on schedule, in case that he couldn't pay, the electricity transmission can be turned off autonomously from the distant server. The user can monitor the energy consumption in units from a web page by providing device IP address [1].
\end{abstract}

Keywords: Energy Meter, Microcontroller, Optocoupler, Wi-fi Module, Meter Reading, Consumer, LED Blinking, Server, Web page.

\section{INTRODUCTION}

In India, the electricity usage is very high. And there is no such system that can take the reading on its own. Energy meter monitoring and keeping track of energy consumption is generally done manually. This process is quite complex, it sometimes produces few problems due to human errors. The problems such as retaking reading may cause, but the bigger problem is in case of big apartment. In these apartments as there are a number of residents and everyone is having an Energy Meter, the number of meters is also high. These meters are connected in matrix form. So, it is quite difficult for both the electricity board and the consumer to identify their own meter. Also for the consumer to know his daily use of electricity, has to go to the meter and check for the readings, which makes this stuff a bit annoying [2].

So, automating this process will be very useful. This will allow user to monitor reading by the internet access. This automated system is such designed that it can access the Energy Meter of every consumer directly without any human intervention. It will take the reading itself and will display it using server this will make consumer also to access their account on server and check their usage and bill even on daily basis and at will disconnect the connection if bill is not paid in time. Automated system will provide unit consumed and the cost of the unit. This also will be useful for the smart city programme undertaken by government. This paper is presenting the automated Electric Energy Meter inspecting and billing system. This system will help creating a transparent and a consumer-friendly environment [2].

\section{LITERATURE SURVEY}

The traditional way of taking meter reading is by using human intervention. In this process of taking meter reading a person from the electricity board takes the photo of the meter having the reading. Then this reading from the photo is submitted at board and depending upon the previous reading bill is made [4]. This process is a monthly process, so consumer never get to know the electricity usage from the bill for the desired time span unless he checks the Energy meter himself [2].

So this process sometimes produces inconvinience in the mind of the consumer about the bill. Also it is difficult for the person taking the meter reading to take the reading in big apartments as the meters are connected in matrix form. The major cause of this problem is human intervention so to eliminate this problem it is desired to eliminate this human intervention. And this is done by automating this system[2].

\section{WORKING PRINCIPLE}

The basic components used in this research are ATMEGA-328, optocoupler, Energy Meter, Wi-fi module (ESP8266). Initially, the anode and cathode are connected to the red LED of electric energy meter with opto-coupler. Now as shown in the block diagram this opto-coupler will sense led blinking and will pass the input accordingly to micro-controller ATMEGA-328.

As for an Energy Meter, when LED blinks for 3200 times, the meter will increase the reading by 1 so inside microcontroller, counter will start which will count +1 whenever opto-coupler will give output [6], [7].

Initially the count will be zero. And then it will count ahead. As soon as counter value reaches to 3200 , then a command will passed to the server to increase unit by +1 . This is done by using Wi-fi module. A website is created so as to display this data on the internet. This website will be connected with server, so that whenever data will change in database it will show the actual reading of meter accordingly. The consumer will access his own reading by using a unique code given for each Energy Meter. 


\section{BLOCK DIAGRAM}

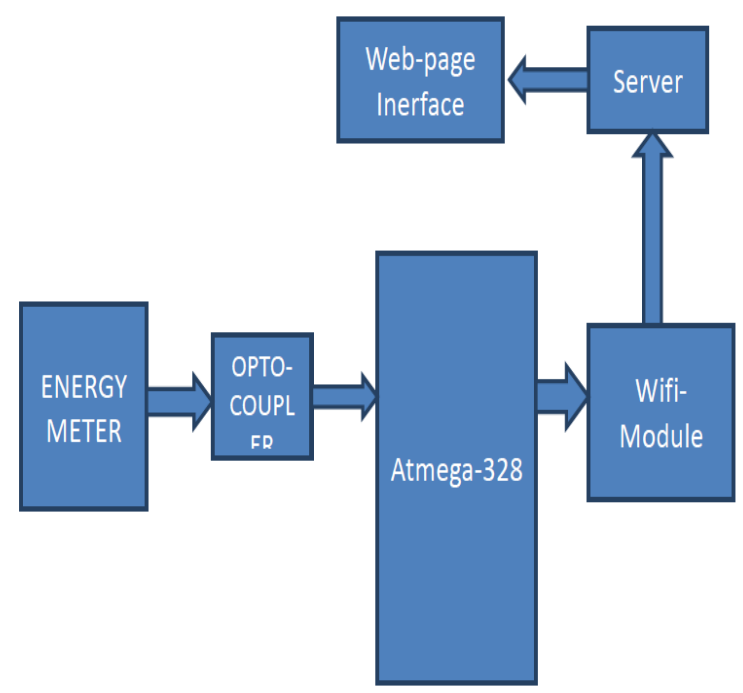

Fig. 1. Block Diagram of the system

\section{SYSTEM OVERVIEW}

The components used are ATMEGA-328, optocoupler, Energy Meter, Wi-Fi module (ESP8266).

\section{A. ATMEGA-328}

The Atmel picoPower ATmega328/P is a low power CMOS 8bit microcontroller based on the AVR® enhanced RISC architecture. By executing powerful instructions in a single clock cycle, the ATmega328/P achieves throughputs close to 1MIPS per MHz. This empowers system designer to optimize the device for power consumption versus processing speed [12].

\section{B. Energy Meter}

An energy or electric meter is a device that measures the amount of electrical energy consumed by a residence, business, or an electrically-powered device.

There are many types of Energy Meter available in market, but in this research a specific type of Energy Meter is used. This research has used a $3200 \mathrm{imp} / \mathrm{kwh}$ type meter. When red LED will blink 3200 times, will read as 1 unit [3], [4].

\section{OPTOCOUPLER}

In electronics, an opto-isolator, also called an optocoupler, photocoupler, or optical isolator, is a component that transfers electrical signals between two isolated circuits by using light. Optocoupler is a 6 pin IC. It has a 1 LED and Transistor [10].

\section{Wifi module(ESP 8266)}

The ESP8266 is a low-cost Wi-Fi chip with full TCP/IP stack and MCU (Micro Controller Unit) capability produced by Shanghai-based Chinese manufacturer, Espressif Systems [9].
It is a 32-bit RISC CPU: TensilicaXtensa LX106 running at $80 \mathrm{MHz}$. Also, it is having $64 \mathrm{KiB}$ of instruction RAM, $96 \mathrm{KiB}$ of data RAM. its External QSPI flash - $512 \mathrm{KiB}$ to $4 \mathrm{MiB}^{*}$ (up to $16 \mathrm{MiB}$ is supported) is very useful in this research. It is also having 16 GPIO pins, SPI, $\mathrm{I}^{2} \mathrm{C}, \mathrm{I}^{2} \mathrm{~S}$ interfaces with DMA (sharing pins with GPIO) [8].

It has Integrated TR switch, balun, LNA, power amplifier and matching network [13].

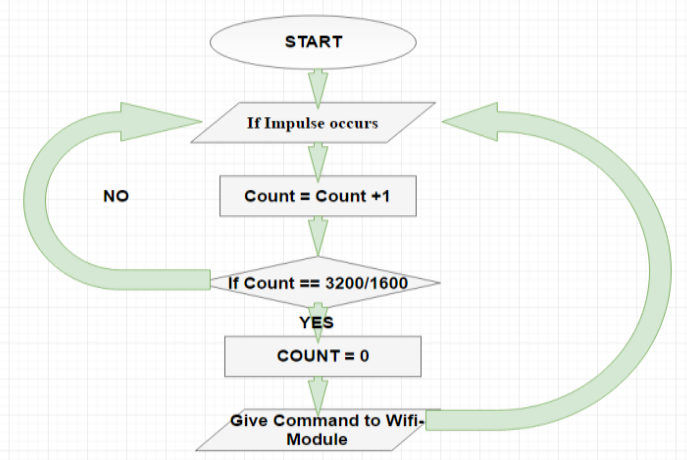

Fig.2. Flow chart

Whenever impulse led of electric meter will glow then through opto-coupler microcontroller will sense that input and it will increase its counter value by one. Depending on the type of electric meter i.e. of 3200/1600 it will check that if threshold counter is reached or not.

If threshold counter reached then it will send command to server through Wi-Fi module for unit increment making its counter value to zero and will go to step number 2 . And if counter not reached to threshold then it will go to step number 2 and it will again follow above mentioned steps. This process is shown in fig. 2.

\section{SIMULATION RESULTS}

The following diagram (fig. 2) shows the proteus simulation of the system we have designed in this research. The primary circuit diagram is simulated below. The secondary part of this project is of Wi-Fi module [12].

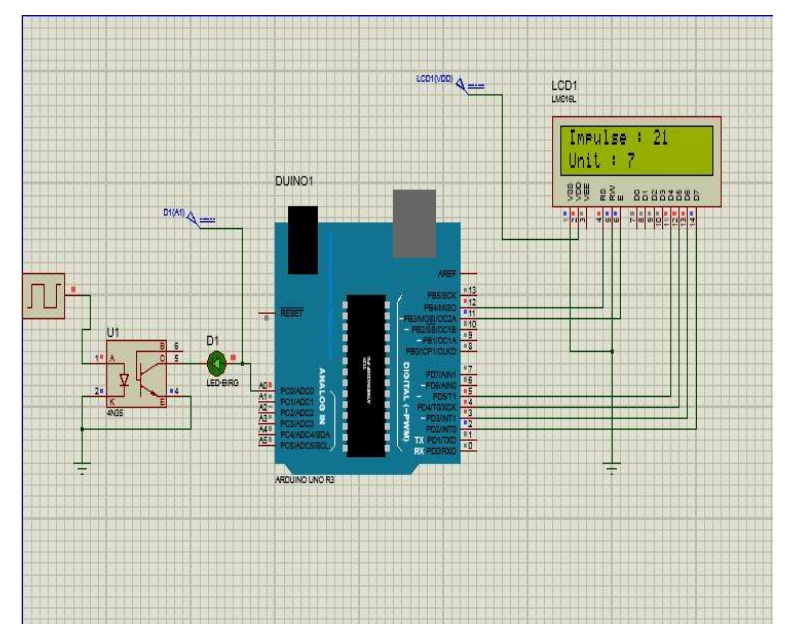

Fig. 2. Proteus Simulation of the system 


\section{DATABASE CREATION}

This project needs to store information of consumer and its usage units on the server. So, by using MySQL language the database has been created for storing all related information of the consumer. The database can be handled by the service provider. The information will help to show the billing amount to customer. The following diagram (fig. 3) shows database used in this project [11].

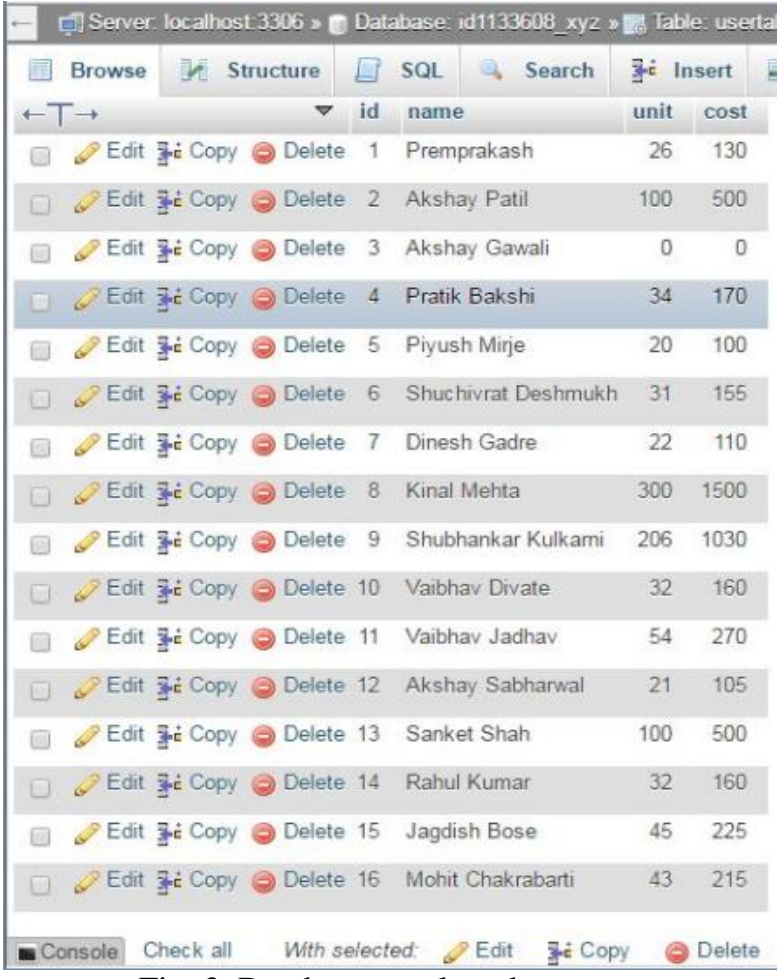

Fig. 3. Database panel on the server

\section{RESULTS AND DISCUSION}

This experiment results both hardware and software part. First of all, the LED blinking has been successfully coupled to the counter of the microcontroller by the optocoupler. Then this data is being displayed by the WiFi module on server on the internet. The user interface of website accessed by consumer is shown in fig. $4 \&$ fig. 5 as follows. HyperText markup language, HTML is front end language. It is the part which is visible to the user. It may consist of GUI which provides better user interface for the user.

PHP is a general-purpose scripting language that is especially suited to server-side web development, in which case PHP generally runs on a web server. Any PHP code in a requested file is executed by the PHP runtime, usually to create dynamic web page content or dynamic images used on websites or elsewhere [14].

PHP is basically back end language. Its main task is to connect html page to actual remote webserver. It acts as interface between user window and actual server(database).

\section{Energy meter Reading Portal}

*Enter your meter $\mathbf{D}$ number for cheking exact meter unit

$$
\text { Enter meter id: } 1
$$

GO

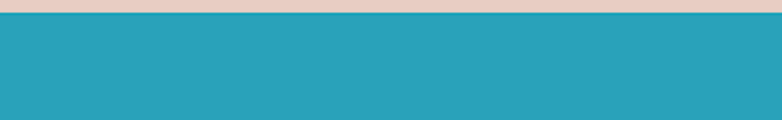

Fig. 4. Website window for Id Entry

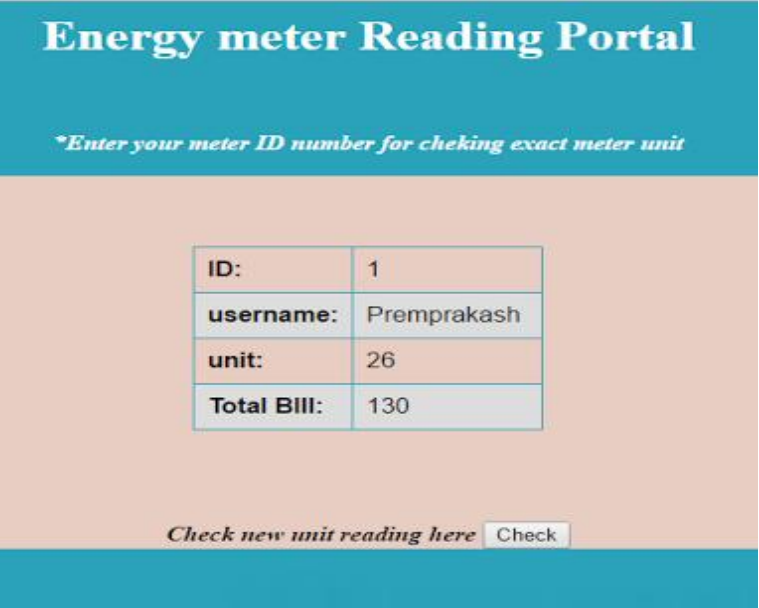

Fig. 5. Website window for Energy Meter readings

The designed website for displaying the units and respective information worked properly. Its seen that the once the unique code given for every consumer is entered at the website yield the correct reading and the correct bill also.

\section{CONCLUSION}

Thus, an automated system for Energy Meter reading and Billing has been developed. This system is helpful in digitisation of traditional system. It reduced the human efforts as well as it eliminated the human dependency for the process. By implementing this system, the complexity in big apartments is reduced to a great extent. Also, this system can take a major share in the government's 'DIGITAL INDIA' campaign.

\section{ACKNOWLWGEMENT}

We would like to express our special thanks of gratitude to our teacher Prof. V. U. Patel, who gave us the golden opportunity to do this wonderful project, which also helped us in doing a lot of Research and we came to know 
about so many new things. We thank Prof. V. U. Patel for her valuable guidance for the paper.

\section{REFERENCES}

[1] B.C.Koay, S.S.Cheah, Y.H.Sng, P.Shum, Y.C.Tong, X.Y.Wang, Y.X.Zuo and H.W.Kuek "Design and implementation of Bluetooth energy meter", IEEE proceeding of the 4th international joint conference of the ICICS, vol.3, pp.1474-1477, Dec.2003.

[2] Landi C., Dipt. d.Ing.,dell inf. Secondauniv. di Napoli, Aversa Italy, Morela, P.; lannilo G, "ARM based energy management system using smart meter and web server", IEEE Instrumentation and Measurement Technology conference, pp.1-5, May-2011.

[3] "IoT based energy meter reading, Theft detection and disconnection using PLC modem and power optimization." by DarshanIyer, Dr. K. A. Radhakrishna Rao. Websites:

[4] Vaishnavi S. Gunge, Pratibha S. Yalagi, Walchand Institute of Technology Solapur, "Smart Home Automation: Literature Review", International Journal of Computer Applications (0975 8887) National Seminar on Recent Trends in Data Mining (RTDM 2016)

[5] H.G. Rodney Tan, C. H. Lee, and V. H. Mok, Automatic Power Reading Using GSM Network, The 8th International Power Engineering Conference (IPEC2007). Web.30 November2010.

[6] D. Mohan Kumar, Working of Electronic Energy Meter, [https://dmohankumar.wordpress.com/2010/04/18/electronicenergy-meter-2/], accessed on 8 January,2017.

[7] Counting of pulses in microcontroller according to optocoupler output, [http://www.edgefxkits.com/gsm-based-monthly-electricityenergy-meter-billing-with-sms-upon-gsm-with-user-programablenumber-features-together-with-onsite-display-to-the-user], accessed on 15 January, 2017.

[8] Basic Information \& Operation of ESP8266, [https://www.espruino.com/ESP8266], accessed on 22 January,2017.

[9] Eric Brown, Linux and Open Source Hardware for IoT. [https://www.linux.com/news/linux-and-open-source-hardware-iot], accessed on 29 January, 2017.

[10] Optocoupler [http://www.electronicstutorials.ws/blog/optocoupler.html], accessed on 18 January,2017.

[11] PHP MySQL Tutorial, [http://www.mysqltutorial.org/php-mysq1/], accessed on 5 February, 2017.

[12] Getting Started with Arduino, Book by Massimo Banzi.

[13] Getting Started with the Internet of Things: Connecting Sensors and Microcontrollers to the Cloud, by Cuno Pfister

[14] PHP and MySQL Web Development Book by Luke Welling 